\title{
Questionamento em manuais escolares de Ciências: desenvolvimento e validação de uma grelha de análise ${ }^{1}$
}

\section{Questions in Science textbooks: development and validation of a checklist}

\author{
Laurinda Leite ${ }^{2}$ \\ Luís Dourado ${ }^{3}$ \\ Sofia Morgado 4 \\ Teresa Vilaça ${ }^{5}$ \\ Clara Vasconcelos ${ }^{6}$ \\ Maria Arminda Pedrosa ${ }^{7}$ \\ Ana Sofia Afonso ${ }^{8}$
}

\section{RESUMO}

Questões são enunciados que requerem uma resposta refletida e que desempenham diversas funções educativas, incluindo o despoletar novas aprendizagens. Neste caso, o seu uso enquadra-se na Aprendizagem

\footnotetext{
${ }^{1}$ Trabalho no âmbito do projeto Educação em Ciências para a Cidadania através da Aprendizagem Baseada na Resolução de Problemas (PTDC/CPE-CED/108197/2008), financiado pela FCT no âmbito do Programa Operacional Temático Factores de Competitividade (COMPETE) do quadro Comunitário de Apoio III e comparticipado pelo Fundo Comunitário Europeu (FEDER).

${ }^{2}$ Doutora, Instituto de Educação, Universidade do Minho, Braga, Portugal. E-mail: lleite@ie.uminho.pt.

${ }^{3}$ Doutor, Instituto de Educação, Universidade do Minho, Braga, Portugal. E-mail: ldourado@ie.uminho.pt.

${ }^{4}$ Mestranda, Instituto de Educação, Universidade do Minho, Braga, Portugal. E-mail: sofiamorgado@ie.uminho.pt.

${ }^{5}$ Doutora, Instituto de Educação, Universidade do Minho, Braga, Portugal. E-mail: tvilaca@ie.uminho.pt.

${ }^{6}$ Doutora, Faculdade de Ciências, Universidade do Porto, Portugal. E-mail: csvascon@fc.up.pt.

${ }^{7}$ Doutora, Faculdade de Ciências, Universidade de Coimbra, Portugal.E-mail: apedrosa@ci.uc.pt.

${ }^{8}$ Doutora, Instituto de Educação, Universidade do Minho, Braga, Portugal. E-mail: aafonso@ie.uminho.pt.
} 
Baseada na Resolução de Problemas (ABRP, do inglês, Problem-Based Learning, PBL), que coloca o aluno no centro dos processos de ensino e aprendizagem, atribuindo-lhe um papel ativo na aprendizagem de novo conhecimento. Atendendo à influência que os manuais exercem nas práticas de ensino, a questão que se coloca é a de saber em que medida as questões incluídas nos manuais escolares de Ciências podem fomentar um ensino orientado para a ABRP. Neste texto, descrever-se-á o processo de construção e validação de uma grelha de análise de questões incluídas em manuais escolares de Ciências com essa finalidade, apresentando-se não só essa grelha, mas também, a título ilustrativo, uma aplicação da mesma a um tópico de Ciências, $8^{\circ}$ ano, abordado nas duas disciplinas desta área.

Palavras-chave: questionamento; manuais escolares; grelha de análise; aprendizagem baseada na resolução de problemas.

\begin{abstract}
Questions require a thoughtful answer and can play diverse educational roles, such as stimulating the learning of new knowledge, as is the case in Problem-Based Learning (PBL) contexts. In this context, the student is placed at the center of the teaching and learning processes and plays an active role in the learning of new knowledge. Bearing in mind the influence that textbooks exert on teaching practices, it is worthwhile questioning to which extent questions included in school science textbooks promote a PBL oriented teaching approach. This paper describes the development and validation of a checklist for analyzing the questions included in science textbooks. After introducing the checklist, an example of its application to a science unit assigned to two junior high school science courses $\left(8^{\text {th }}\right.$ grade) is given, approaching the two disciplines in the area.
\end{abstract}

Keywords: questioning; school textbooks; checklist; problem-based learning.

\title{
Introdução
}

Apesar dos grandes desenvolvimentos e da crescente divulgação das Tecnologias da Informação e Comunicação (TIC), o manual escolar continua a ser um recurso didático muito utilizado nas escolas, designadamente no ensino das Ciências. A este facto não será alheio o reconhecimento que a própria Lei de Bases do Sistema Educativo, recentemente revista (Lei ${ }^{\circ}{ }^{49} / 2005$, de 30 
de agosto), faz do manual escolar, considerando-o um dos mais importantes recursos educativos. Uma evidência de que o próprio Ministério da Educação reconhece a importância do manual escolar enquanto recurso didático reside no facto de se ter iniciado o processo de avaliação e certificação de manuais escolares, processo que, no entanto, não alcançou ainda os manuais escolares da área das Ciências Físicas e Naturais, do $3^{\circ}$ ciclo do Ensino Básico. Embora os manuais escolares se destinem aos alunos, a investigação sugere que eles influenciam as práticas dos professores (CHIAPPETTA; FILLMAN, 2007) que, em muitos casos, o encaram como se fosse o currículo, currículo que os manuais escolares deveriam servir reinterpretando-o com fidelidade. Como argumentámos em outro local (DOURADO; LEITE, 2010), esta reinterpretação "deveria ser o mais adequada possível, não só em termos de temas e conceitos a abordar mas também nas formas de os abordar" (p. 1).

O Currículo Nacional do Ensino Básico (CNEB), que entrou em vigor no início do século XXI (DEB, 2001), atribui um papel ativo aos alunos e defende, entre outros, o desenvolvimento da literacia científica, das inter-relações Ciências-Tecnologia-Sociedade e Ambiente, do raciocínio crítico e de competências de questionamento, de pesquisa e de resolução de problemas. Os próprios temas organizadores do CNEB são apresentados através de questões. Esta forma de apresentar os temas, aliada à defesa da pesquisa e da resolução de problemas anteriormente referidas, remete para um ensino orientado para a Aprendizagem Baseada na Resolução de Problemas (ABRP), em inglês designado por Problem-Based Learning (PBL), onde os alunos aprendem novos conceitos resolvendo problemas (LEITE; AFONSO, 2001; LAMBROS, 2004).

Os manuais escolares portugueses recorrem a questões quando desenvolvem os diversos temas programáticos (LEITE; COSTA; ESTEVES, 2008). Aceitando a perspetiva de Zucker et al. (2010) sobre a influência do texto do manual na moldagem do discurso entre professores e alunos, dependendo do modo como o manual escolar lida com o questionamento pode, direta ou indiretamente, fomentar ou dificultar a concretização, ao nível da sala de aula, da filosofia adotada pelo CNEB. Neste contexto, a questão que se coloca é a de saber em que medida o modo como os manuais escolares lidam com o questionamento é, ou não, consistente com o preconizado no CNEB. Não se conhecendo estudos que se centrem de modo exaustivo e sistemático na análise de tal aspeto, este artigo visa apresentar o desenvolvimento e a validação de uma grelha de análise das questões incluídas em manuais escolares de Ciências, apresentando-se não só essa grelha, mas também, a título ilustrativo, uma aplicação da mesma a um tópico de Ciências. 


\section{Fundamentação teórica}

\section{Questionamento: formas e potencialidades}

Questionar corresponde a manifestar a vontade de obter do interlocutor uma resposta, mas uma resposta que exija reflexão (RODRIGUES, 1998). Assim, questionar uma pessoa é colocar essa pessoa a pensar sobre algo. As questões são, portanto, enunciados que requerem uma resposta que exige alguma reflexão (ou seja, trabalho cognitivo) por parte do respondente (PEDROSA DE JESUS; MOREIRA, 2009), podendo apresentar ou não a forma interrogativa. Neste sentido, pode distinguir-se questão de pergunta e afirmar-se que nem todas as perguntas são questões, pois algumas perguntas (ex.: Como te chamas?) são de resposta direta e imediata, não exigindo tal reflexão. Por outro lado, nem todas as questões são perguntas, pois pode solicitar-se a alguém o pensamento sobre algo simplesmente ordenando-lhe que desencadeie uma ação com vista a alcançar um determinado objetivo (ex.: Identificar procedimentos a adotar em casa com vista à redução, em $10 \%$, do consumo de energia, sem reduzir a qualidade de vida das pessoas). Assim, os enunciados das questões podem ser apresentados, ou não, na forma de pergunta, ou seja, com ou sem interrogação no final e as perguntas podem ou não ser questões, dependendo do seu conteúdo e da consequente exigência cognitiva que comportam.

Em contexto de educação formal, são diversas as funções desempenhadas pelas questões (WRAGG; BROWN, 2001) e que vão da tradicional função de avaliação das aprendizagens até funções cognitivas, relacionadas com a promoção da compreensão e o desenvolvimento do pensamento crítico, ao reforço da atenção e do controlo comportamental e ao despertar a curiosidade por um determinado tema.

Conceptualizadas como enunciados que fazem o respondente pensar para obter uma resposta, no contexto educativo, as questões podem passar a desempenhar outras funções. Entre elas destaca-se a de despoletar novas aprendizagens. Esta é uma das funções fundamentais que lhes é atribuída no quadro do ensino orientado para a ABRP. Este tipo de ensino coloca o aluno no centro dos processos de ensino e de aprendizagem, atribuindo-lhe um papel ativo na aprendizagem de novo conhecimento através da resolução de problemas que não são mais do que questões. Efetivamente, se um enunciado é passível de ser classificado como problema, então não pode ter resolução direta e linear, mas colocará um obstáculo ao resolvedor (CHIN; CHIA, 2004), obrigando-o a pensar e a trabalhar para encontrar uma solução, caso esta exista. 
Existem diversas taxonomias de questões que foram recentemente sintetizadas por alguns autores (LOUREIRO, 2008; OLIVEIRA, 2008). Uma dessas taxonomias, proposta por Dahlgren e Öberg (2001) e já usada em alguns estudos realizados em Portugal, classifica as questões em cinco categorias, atendendo à exigência cognitiva que colocam: as Questões Enciclopédicas, que requerem uma resposta simples e direta e que têm a ver com significados, superficiais, de termos, podendo, em alguns casos, ser respondidas apenas com "Sim" ou "Não"; as Questões de Compreensão, que não têm uma resposta direta e que têm a ver com o significado de conceitos; as Questões Relacionais, que exigem o estabelecimento de relações entre dois ou mais elementos, designadamente de tipo causa e consequência; as Questões de Avaliação, que envolvem comparação, avaliação e emissão de um juízo de valor, com base em critérios; e, finalmente, as Questões de Procura de Solução, que visam à compreensão das partes de um problema complexo e cuja resposta requer a resolução do problema. Note-se que, com exceção das questões enciclopédicas (que, atendendo à sua reduzida exigência cognitiva, não são verdadeiras questões), os restantes tipos de questões exigem reflexão e trabalho cognitivo por parte do interlocutor que pretenda responder-lhes.

$\mathrm{O}$ tema do questionamento tem sido trabalhado em diversas perspetivas, designadamente interação em aulas de Ciências (FERREIRA, 2010), questões formuladas por professores (WRAGG; BROWN, 2001; ALLEN; TANNER, 2002), questões formuladas por alunos (COSTA et al., 2000; DAHLGREN; ÖBERG, 2001; LEITE; PALMA, 2006), questões suscitadas por contextos problemáticos associados à ABRP (LEITE; PALMA, 2006; LEITE; LOUREIRO; OLIVEIRA, 2010) e questões incluídas em manuais escolares (LEITE; COSTA; ESTEVES, 2008; DOURADO; LEITE, 2010; LEITE; DOURADO; MORGADO, 2011; VASCONCELOS et al., 2011). Centrados nas perguntas formuladas e nos resultados dos estudos referidos, constata-se que os professores fazem muitas perguntas de nível cognitivo baixo (e que, por isso, não serão verdadeiras questões) e que, frequentemente, não pretendem que os alunos thes respondam. Os alunos, por sua vez, não estão habituados a fazer perguntas, mas quando lhes é dada oportunidade, formulam perguntas que exigem raciocínio e mobilização de conhecimentos diversos, ou seja, que podem ser consideradas questões. Os manuais escolares incluem questões que, na maior parte dos casos, são de nível cognitivo baixo. Finalmente, refira-se que diversos contextos problemáticos levam os alunos a formular diferentes números de perguntas, cuja qualidade (em termos de exigência cognitiva) também varia com a natureza e o conteúdo informativo do contexto. 


\section{Questionamento em manuais escolares de Ciências}

Os manuais escolares de Ciências incluem questões em diversos lugares e com diversas funções. Tradicionalmente, os manuais escolares usavam grandes números de questões para efeitos de avaliação de aprendizagem. Era nas questões incluídas no final das unidades didáticas que se centravam os estudos (ex. CORREIA, 1996). Pretendia-se com eles averiguar se os enunciados que apresentavam correspondiam a exercícios rotineiros, para treino de conhecimentos adquiridos, ou se constituíam oportunidades para os alunos aplicarem (e, assim, também aprofundarem) conhecimentos previamente adquiridos a situações novas.

Com a divulgação de perspetivas de ensino centrado nos alunos e com a adoção de currículos que visam ao desenvolvimento da literacia científica dos alunos e defendem abordagens CTS (ciência-tecnologia-sociedade) ou CTS-A (ciência-tecnologia-sociedade-ambiente), os estudos sobre o questionamento em manuais escolares passaram a centrar-se mais no antes e no durante o ensino. Quando está em causa conseguir que o próprio aluno aprenda a aprender, aprenda a resolver problemas e se aperceba das inter-relações entre as Ciências, a Tecnologia, a Sociedade e o Ambiente, a eventual existência de questões no final da unidade centradas nestes aspetos não seria suficiente. Atingir esse objetivo requer uma mudança radical nas metodologias de ensino que deixam de ter a função de apresentar o conhecimento aos alunos e que devem passar a orientá-los na busca desse conhecimento, acompanhada pelo desenvolvimento de competências procedimentais e de raciocínio que lhes permitam usar de forma seletiva e crítica a nova informação com que contactam, sistematizando-a e integrando-a com a informação prévia de que dispunham.

Neste contexto, faz sentido que as investigações centradas no questionamento em manuais escolares incidam nas questões que surgem antes e durante o desenvolvimento dos temas, pois são essas que informam sobre a qualidade mediadora do manual relativamente ao currículo e programas, no que concerne ao questionamento.

Apesar de se verificar que os manuais escolares atuais evidenciam uma maior preocupação com a literacia científica do que os de há 15 anos atrás, uma vez que procuram mostrar como os cientistas pensam e agem, e que atribuem aos alunos um papel mais ativo (CHIAPPETTA; FILLMAN, 2007), Kahveci (2010) observou que nos manuais escolares de Ciências predominam questões de baixo nível cognitivo, sendo maior a presença de questões de input, que visam recordar a informação, do que questões de output, que se destinam à reflexão e à avaliação. Embora recorrendo a diferentes categorias de análise, investigações realizadas com manuais escolares portugueses (LEITE; COSTA; ESTEVES, 
2008; DOURADO; LEITE, 2010; LEITE; DOURADO: MORGADO, 2011; VASCONCELOS et al., 2011) sugerem que os manuais escolares incluem um número elevado de questões, que tende a ser superior no caso dos manuais escolares de Ciências Físico-Químicas do que de Ciências Naturais, mas que essas questões são, na sua grande maioria, de baixo nível cognitivo e/ou raramente são utilizadas como ponto de partida para o desenvolvimento dos temas e, logo, pouco consistentes com uma perspetiva de ensino orientado para a ABRP.

\section{Desenvolvimento da grelha para análise das questões incluídas em manuais escolares de Ciências}

O desenvolvimento da grelha de análise tomou em consideração o conhecimento prévio dos manuais de Ciências portugueses e as funções das questões. Assim, para o desenvolvimento da grelha de análise de questões apresentadas em manuais escolares de Ciências (Tabela 1), foram criadas as seguintes oito dimensões de análise: localização das questões; função das questões; nível cognitivo das questões; contexto de incidência das questões; abrangência das questões; respostas às questões; exigência das respostas às questões; e aceitação de diversidade de respostas.

As primeiras cinco dimensões incidem na análise das próprias questões e as três últimas na análise do conteúdo das respostas a essas questões. As dimensões incluem algumas subdimensões que, em alguns casos, foram ainda mais especificadas, de modo a captar a diversidade de formas como as questões são utilizadas nos manuais escolares.

A Tabela 1 apresenta as dimensões e subdimensões, bem como uma descrição sumária destas, de modo a tornar percetível o significado de cada uma.

Uma primeira versão da grelha foi usada separadamente por alguns dos autores a fim de detetar potencialidades e limitações da mesma quando aplicada a diversos temas abordados em manuais escolares de diversos anos de escolaridade. Dessas experiências foram surgindo dúvidas e questões que foram sendo discutidas pelo grupo de investigadores, que conduziram a sucessivas reformulações, por vezes pontuais, da grelha e que permitiram elaborar a versão das explicações de cada (sub)dimensão que se apresenta na coluna intitulada Observações (Tabela 1). Na secção que se segue, apresentar-se-á uma aplicação da grelha à análise do questionamento incluído em seis manuais escolares das duas disciplinas de Ciências do $3^{\circ}$ ciclo do Ensino Básico, de modo a validar a grelha. 


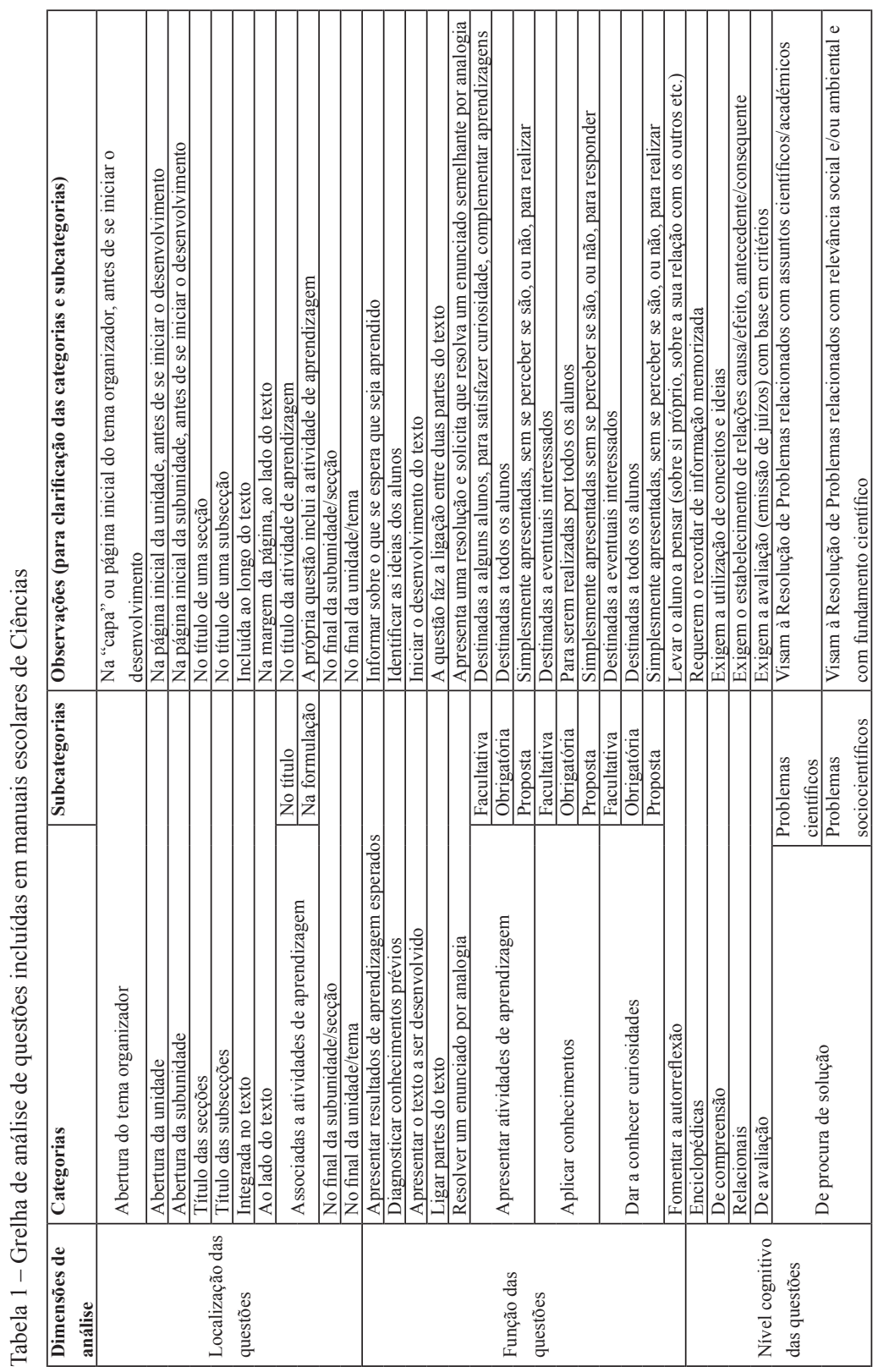




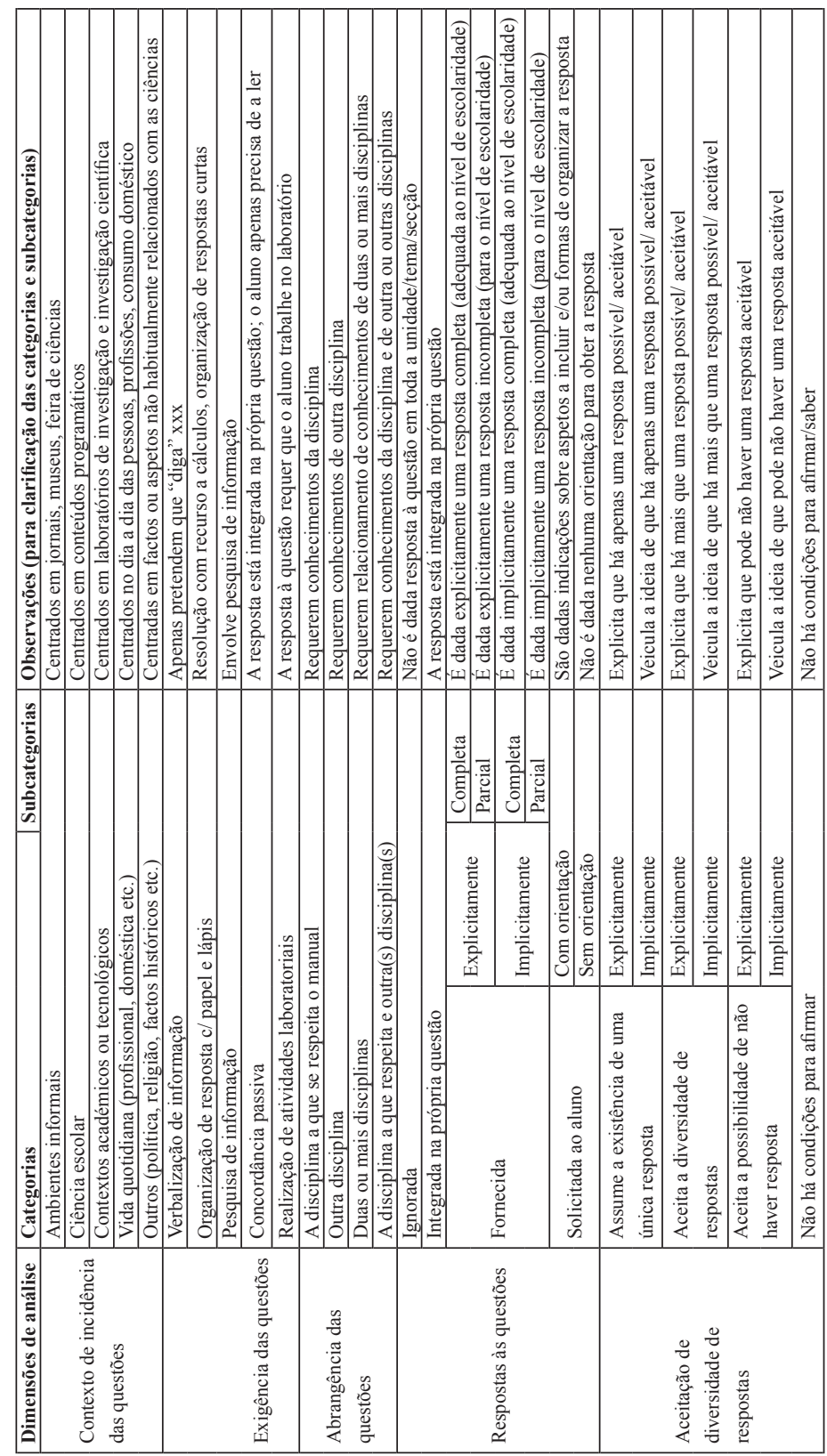




\section{Validação da grelha}

\section{Método de validação}

Para validar a grelha de análise das questões incluídas nos manuais escolares de Ciências, utilizaram-se três manuais escolares de Ciências Naturais $(\mathrm{CN})$ e outros três de Ciências Físico-Químicas (CFQ), ou seja, manuais de duas disciplinas que não só têm tradições diferentes no que respeita à resolução de problemas/exercícios, como podem diferir entre si no que respeita ao questionamento, como a investigação tem sugerido. Os manuais selecionados são de três editoras diferentes e também de autores diferentes. Foi selecionada a unidade Gestão Sustentável de Recursos, uma das unidades didáticas do tema organizador Sustentabilidade na Terra $\left(8^{\circ}\right.$ ano, frequentado por alunos com 13 ou 14 anos de idade), um dos quatro temas contemplados no Currículo Nacional do Ensino Básico. Aquela unidade foi selecionada por ser comum às duas disciplinas e pelo elevado impacto que pode ter aos níveis social, científico, tecnológico e ambiental, o que pode facilitar a inclusão de questões científicas a par com questões sociocientíficas (relevantes para introduzir um ensino orientado para a ABRP), bem como a sua contextualização em termos profissionais, sociais ou outros. Assim, se for válida, a grelha proposta deve permitir evidenciar as diferenças entre os manuais, o que indicará que funciona enquanto instrumento de análise que se pretende capaz de discriminar questionamentos que sejam efetivamente diferentes.

Análise, com base na grelha, do questionamento apresentado pelos manuais escolares

$\mathrm{Na}$ análise das questões incluídas nos manuais escolares de Ciências, não foram tidas em atenção as questões existentes no fim de cada unidade e/ou subunidade, uma vez que a função destas questões é a de fomentar a aplicação e/ou a de permitir a avaliação das aprendizagens realizadas e não a de incentivar o ensino orientado para a ABRP. Também não foram tidas em atenção as questões incluídas dentro de uma atividade, uma vez que se considera que, embora relevantes para a análise das atividades didáticas propostas pelo manual escolar, não são relevantes para uma análise em que se pretenda averiguar em que medida o manual promove, ou não, uma perspetiva de ensino orientado para a ABRP. Foram, no entanto, consideradas todas as perguntas, pois, apesar de algumas delas não poderem ser consideradas questões, por não exigirem reflexão, importa ver se a grelha as consegue identificar e separar das restantes. A identificação 
e a classificação das questões com base na grelha foram efetuadas por dois dos autores, separadamente, e depois confrontadas, de modo a identificar e resolver eventuais discrepâncias. Os casos mais difíceis foram discutidos com outros autores, de modo a resolver as divergências existentes, alterando a classificação inicial ou ajustando as categorias de análise.

A Tabela 2, além de apresentar o número de questões consideradas na análise que cada um dos manuais inclui na unidade em causa, apresenta também o resultado da análise da localização dessas questões, nos diversos manuais escolares selecionados.

Tabela 2 - Localização das questões incluídas nos manuais escolares (\%)

\begin{tabular}{|c|c|c|c|c|c|c|c|}
\hline \multicolumn{2}{|l|}{ Local } & $\begin{array}{l}\text { CFQ 1 } \\
\left(\mathrm{n}_{1}=27\right)\end{array}$ & $\begin{array}{l}\text { CFQ 2 } \\
\left(\mathrm{n}_{2}=3\right)\end{array}$ & $\begin{array}{l}\text { CFQ 3 } \\
\left(\mathrm{n}_{3}=20\right)\end{array}$ & $\begin{array}{c}\text { CN 1 } \\
\left(\mathrm{n}_{1}=98\right) \\
\end{array}$ & $\begin{array}{c}\text { CN 2 } \\
\left(\mathrm{n}_{2}=16\right)\end{array}$ & \begin{tabular}{|c|} 
CN 3 \\
$\left(\mathrm{n}_{3}=11\right)$ \\
\end{tabular} \\
\hline \multicolumn{2}{|c|}{ Abertura do tema organizador } & 7,4 & 33,4 & 0,0 & 3,1 & 0,0 & 0,0 \\
\hline \multicolumn{2}{|l|}{ Abertura da unidade } & 0,0 & 0,0 & 10,0 & 0,0 & 31,2 & 0,0 \\
\hline \multicolumn{2}{|l|}{ Abertura da subunidade } & 18,5 & 0,0 & 0,0 & 0,0 & 0,0 & 0,0 \\
\hline \multicolumn{2}{|l|}{ Título das secções } & 0,0 & 0,0 & 0,0 & 0,0 & 0,0 & 0,0 \\
\hline \multicolumn{2}{|l|}{ Título das subsecções } & 0,0 & 0,0 & 15,0 & 2,0 & 0,0 & 0,0 \\
\hline \multicolumn{2}{|l|}{ Integrada no texto } & 51,9 & 33,3 & 65,0 & 9,2 & 0,0 & 63,6 \\
\hline \multicolumn{2}{|l|}{ Ao lado do texto } & 22,2 & 0,0 & 0,0 & 82,7 & 0,0 & 0,0 \\
\hline \multirow[b]{2}{*}{ Associadas a atividades } & No título & 0,0 & 0,0 & 0,0 & 2,0 & 68,8 & 36,4 \\
\hline & $\begin{array}{l}\mathrm{Na} \text { formulação } \\
\text { da atividade }\end{array}$ & 0,0 & 33,3 & 10,0 & 1,0 & 0,0 & 0,0 \\
\hline \multicolumn{2}{|l|}{ Final da unidade } & 0,0 & 0,0 & 0,0 & 0,0 & 0,0 & 0,0 \\
\hline
\end{tabular}

Constata-se que o número e a localização das questões são muito diversificados no conjunto dos manuais e que há manuais de CN que contrariam a tendência para a existência de mais questões nos manuais de CFQ anteriormente referida. O manual $\mathrm{CN} 1$ apresenta muito mais questões que os manuais de CFQ porque inclui muitas questões na margem da página, ao lado da apresentação do conteúdo, muitas vezes sob a forma de curiosidade. O manual CFQ 2 apresenta um número excepcionalmente baixo de questões, o que é estranho, pois nas outras unidades utilizaram bastantes questões. Possivelmente, os autores não reconheceram o tema como suscitador de questões socioambientais que permitiriam desenvolver o espírito crítico dos alunos e contribuir para formar cidadãos mais preparados.

A Tabela 3 apresenta o resultado da análise da função das questões incluídas nos manuais considerados. As funções são bastante diversificadas e vão desde apresentar resultados de aprendizagem esperados, no início do tema, unidade ou subunidade, a ligar partes do texto, no interior de uma secção, ou a apresentar atividades de aprendizagem (ex.: laboratoriais), ou ainda à aplicação de conhecimentos, assumindo por vezes a forma de curiosidades. 
Tabela 3 - Função das questões incluídas nos manuais escolares (\%)

\begin{tabular}{|c|c|c|c|c|c|c|c|}
\hline \multicolumn{2}{|l|}{ Função das questões } & $\begin{array}{l}\text { CFQ 1 } \\
\left(\mathrm{n}_{1}=27\right)\end{array}$ & \begin{tabular}{|l|} 
CFQ 2 \\
$\left(\mathrm{n}_{2}=3\right)$
\end{tabular} & $\begin{array}{l}\text { CFQ 3 } \\
\left(\mathrm{n}_{3}=20\right)\end{array}$ & \begin{tabular}{|l|} 
CN 1 \\
$\left(n_{1}=98\right)$
\end{tabular} & $\begin{array}{l}\text { CN 2 } \\
\left(\mathrm{n}_{2}=16\right)\end{array}$ & $\begin{array}{l}\text { CN 3 } \\
\left(\mathrm{n}_{3}=11\right)\end{array}$ \\
\hline \multicolumn{2}{|c|}{ Apresentar resultados de aprendizagem esperados } & 25,9 & 33,4 & 10,0 & 3,1 & 31,2 & 0,0 \\
\hline \multicolumn{2}{|c|}{ Apresentar o texto a ser desenvolvido } & 0,0 & 0,0 & 15,0 & 2,0 & 0,0 & 63,6 \\
\hline \multicolumn{2}{|c|}{ Diagnosticar os conhecimentos prévios } & 0,0 & 0,0 & 0,0 & 0,0 & 0,0 & 0,0 \\
\hline \multicolumn{2}{|l|}{ Ligar partes do texto } & 0,0 & 33,3 & 0,0 & 9,2 & 0,0 & 63,6 \\
\hline \multirow{2}{*}{$\begin{array}{l}\text { Apresentar atividades de } \\
\text { aprendizagem }\end{array}$} & Facultativa & 0,0 & 0,0 & 0,0 & 0,0 & 0,0 & 0,0 \\
\hline & Obrigatória & 0,0 & 0,0 & 10,0 & 3,1 & 68,8 & 36,4 \\
\hline \multirow{2}{*}{ Aplicar conhecimentos } & Facultativa & 0,0 & 0,0 & 0,0 & 0,0 & 0,0 & 0,0 \\
\hline & Obrigatória & 51,9 & 33,3 & 65,0 & 0,0 & 0,0 & 0,0 \\
\hline \multirow{2}{*}{ Dar a conhecer curiosidades } & Facultativa & 0,0 & 0,0 & 0,0 & 0,0 & 0,0 & 0,0 \\
\hline & Obrigatória & 22,2 & 0,0 & 0,0 & 82,6 & 0,0 & 0,0 \\
\hline \multicolumn{2}{|c|}{ Resolver um enunciado por analogia } & 0,0 & 0,0 & 0,0 & 0,0 & 0,0 & 0,0 \\
\hline \multicolumn{2}{|l|}{ Autorreflexão } & 0,0 & 0,0 & 0,0 & 0,0 & 0,0 & 0,0 \\
\hline
\end{tabular}

A Tabela 4, que apresenta o nível cognitivo das questões incluídas nos manuais escolares analisados, sugere que, em alguns deles (CFQ 1, CFQ 2 e CN 1), a maior parte das questões não são verdadeiras questões, pois são de tipo enciclopédico e que escasseiam as questões de procura de solução, especialmente frequentes em CN 3.

A Tabela 5 apresenta a análise da apresentação (ou não) da resposta às questões identificadas. Em todos os manuais em análise há questões que não são respondidas. Em alguns (CFQ 2, CN 1 e CN 2) há questões que são apenas parcialmente respondidas e em todos, com exceção de $\mathrm{CN} 3$, há questões cuja resposta é solicitada ao aluno.

Tabela 4 - Nível cognitivo das questões incluídas nos manuais escolares (\%)

\begin{tabular}{|l|c|c|c|c|c|c|c|}
\hline Nível Cognitivo & $\begin{array}{c}\text { CFQ 1 } \\
\left(\mathrm{n}_{1}=27\right)\end{array}$ & $\begin{array}{c}\text { CFQ 2 } \\
\left(\mathrm{n}_{2}=3\right)\end{array}$ & $\begin{array}{c}\text { CFQ 3 } \\
\left(\mathrm{n}_{3}=20\right)\end{array}$ & $\begin{array}{c}\text { CN 1 } \\
\left(\mathrm{n}_{1}=98\right)\end{array}$ & $\begin{array}{c}\text { CN 2 } \\
\left(\mathrm{n}_{2}=16\right)\end{array}$ & $\begin{array}{c}\text { CN 3 } \\
\left(\mathrm{n}_{3}=11\right)\end{array}$ \\
\hline Enciclopédica & 55,6 & 66,7 & 30,0 & 87,8 & 18,7 & 0,0 \\
\hline Compreensão & 37,0 & 33,3 & 45,0 & 11,2 & 68,8 & 9,1 \\
\hline \multicolumn{2}{|l|}{ Relacional } & 7,4 & 0,0 & 20,0 & 0,0 & 12,5 & 9,1 \\
\hline Avaliação & 0,0 & 0,0 & 0,0 & 1,0 & 0,0 & 0,0 \\
\hline \multirow{2}{*}{ Procura de solução } & Problemas científicos & 0,0 & 0,0 & 0,0 & 0,0 & 0,0 & 0,0 \\
\cline { 2 - 8 } & $\begin{array}{l}\text { Problemas } \\
\text { sociocientíficos }\end{array}$ & 0,0 & 0,0 & 5,0 & 0,0 & 0,0 & 81,8 \\
\hline
\end{tabular}


Tabela 5 - Resposta às questões incluídas nos manuais escolares (\%)

\begin{tabular}{|c|c|c|c|c|c|c|c|c|}
\hline \multicolumn{3}{|l|}{ Resposta } & $\begin{array}{l}\text { CFQ 1 } \\
\left(n_{1}=27\right)\end{array}$ & $\begin{array}{l}\text { CFQ 2 } \\
\left(\mathrm{n}_{2}=3\right)\end{array}$ & $\begin{array}{l}\text { CFQ 3 } \\
\left(\mathrm{n}_{3}=20\right)\end{array}$ & $\begin{array}{c}\text { CN 1 } \\
\left(\mathrm{n}_{1}=98\right)\end{array}$ & $\begin{array}{c}\text { CN 2 } \\
\left(\mathrm{n}_{2}=16\right)\end{array}$ & $\begin{array}{c}\text { CN 3 } \\
\left(\mathrm{n}_{3}=11\right)\end{array}$ \\
\hline \multicolumn{3}{|l|}{ Ignorada } & 25,9 & 33,4 & 20,0 & 3,1 & 37,4 & 9,1 \\
\hline \multirow{4}{*}{ Fornecida } & \multirow{2}{*}{ Explicitamente } & Completa & 0,0 & 0,0 & 5,0 & 6,1 & 6,3 & 90,9 \\
\hline & & \begin{tabular}{|l|} 
Parcial \\
\end{tabular} & 0,0 & 33,3 & 0,0 & 2,0 & 0,0 & 0,0 \\
\hline & \multirow{2}{*}{ Implicitamente } & Completa & 0,0 & 0,0 & 0,0 & 1,0 & 25,0 & 0,0 \\
\hline & & Parcial & 0,0 & 0,0 & 0,0 & 3,1 & 25,0 & 0,0 \\
\hline \multirow{2}{*}{$\begin{array}{l}\text { Solicitada } \\
\text { ao aluno }\end{array}$} & \multicolumn{2}{|c|}{ Sem orientação da resposta } & 40,8 & 0,0 & 30,0 & 0,0 & 0,0 & 0,0 \\
\hline & \multicolumn{2}{|c|}{$\begin{array}{l}\text { Com orientação ao nível do } \\
\text { conteúdo/estrutura da resposta }\end{array}$} & 11,1 & 33,3 & 45,0 & 2,0 & 6,3 & 0,0 \\
\hline \multicolumn{3}{|c|}{ Integrada na própria questão } & 22,2 & 0,0 & $\overline{0,0}$ & 82,7 & $\overline{0,0}$ & 0,0 \\
\hline
\end{tabular}

A Tabela 6 sugere que todos os manuais contextualizam questões nas ciências escolares e na vida quotidiana, embora com frequências relativas muito diferentes. Algumas questões têm a ver com política, religião ou factos históricos, mas nenhuma tem a ver com ambientes informais (ex. centros de ciências, oceanários etc.) ou com contextos académicos.

Tabela 6 - Contexto de incidência das questões incluídas nos manuais escolares (\%)

\begin{tabular}{|l|c|c|c|c|c|c|}
\hline Contexto de incidência & $\begin{array}{c}\text { CFQ 1 } \\
\left(\mathrm{n}_{1}=27\right)\end{array}$ & $\begin{array}{c}\text { CFQ 2 } \\
\left(\mathrm{n}_{2}=3\right)\end{array}$ & $\begin{array}{c}\text { CFQ 3 } \\
\left(\mathrm{n}_{3}=20\right)\end{array}$ & $\begin{array}{c}\text { CN 1 } \\
\left(\mathrm{n}_{1}=98\right)\end{array}$ & $\begin{array}{c}\text { CN 2 } \\
\left(\mathrm{n}_{2}=16\right)\end{array}$ & $\begin{array}{c}\text { CN 3 } \\
\left(\mathrm{n}_{3}=11\right)\end{array}$ \\
\hline Ambientes informais & 0,0 & 0,0 & 0,0 & 0,0 & 0,0 & 0,0 \\
\hline Ciência escolar & 59,3 & 33,3 & 45,0 & 24,5 & 31,3 & 18,2 \\
\hline Contextos académicos & 0,0 & 0,0 & 10,0 & 0,0 & 0,0 & 0,0 \\
\hline Vida quotidiana & 37,0 & 66,7 & 45,0 & 67,3 & 62,4 & 81,8 \\
\hline Outros (política, religião, factos históricos etc.) & 3,7 & 0,0 & 0,0 & 8,2 & 6,3 & 0,0 \\
\hline
\end{tabular}

A Tabela 7 apresenta a exigência das questões incluídas nos manuais escolares de Ciências em termos de atividades que é necessário realizar para lhes dar resposta. Constata-se uma grande diversidade de situações, com algumas respostas às questões a exigirem apenas a verbalização de informação e outras a requererem a organização de uma resposta com papel e lápis, a leitura de um texto apresentado no manual, a pesquisa de informação ou a realização de atividades laboratoriais.

Tabela 7 - Exigência das questões incluídas nos manuais escolares (\%)

\begin{tabular}{|l|c|c|c|c|c|c|}
\hline Exigência das questões & $\begin{array}{c}\text { CFQ 1 } \\
\left(\mathrm{n}_{1}=27\right)\end{array}$ & $\begin{array}{c}\text { CFQ 2 } \\
\left(\mathrm{n}_{2}=3\right)\end{array}$ & $\begin{array}{c}\text { CFQ 3 } \\
\left(\mathrm{n}_{3}=20\right)\end{array}$ & $\begin{array}{c}\text { CN 1 } \\
\left(\mathrm{n}_{1}=98\right)\end{array}$ & $\begin{array}{c}\text { CN 2 } \\
\left(\mathrm{n}_{2}=16\right)\end{array}$ & $\begin{array}{c}\text { CN 3 } \\
\left(\mathrm{n}_{3}=11\right)\end{array}$ \\
\hline Verbalização de informação & 25,9 & 33,4 & 40,0 & 14,3 & 93,8 & 100,0 \\
\hline Organização de resposta c/papel e lápis & 51,9 & 33,3 & 40,0 & 2,0 & 0,0 & 0,0 \\
\hline Pesquisa de informação & 0,0 & 0,0 & 20,0 & 1,0 & 0,0 & 0,0 \\
\hline Concordância passiva & 22,2 & 33,3 & 0,0 & 82,7 & 0,0 & 0,0 \\
\hline Realização de atividades laboratoriais & 0,0 & 0,0 & 0,0 & 0,0 & 6,2 & 0,0 \\
\hline
\end{tabular}


A Tabela 8 apresenta a abrangência curricular das questões incluídas nos manuais escolares de Ciências analisados. Constata-se que a maior parte das questões, qualquer que seja o manual, abrange a disciplina a que respeita o manual e outra ou outras disciplinas. Este resultado, algo surpreendente, pode estar relacionado com a natureza interdisciplinar do tema da unidade seleccionada, pelo que, em outras unidades, poderão obter-se resultados diferentes.

Tabela 8 - Abrangência das questões incluídas nos manuais escolares (\%)

\begin{tabular}{|l|c|c|c|c|c|c|}
\hline Abrangência das questões & $\begin{array}{c}\text { CFQ 1 } \\
\left(\mathrm{n}_{1}=27\right)\end{array}$ & $\begin{array}{c}\text { CFQ 2 } \\
\left(\mathrm{n}_{2}=3\right)\end{array}$ & $\begin{array}{c}\text { CFQ 3 } \\
\left(\mathrm{n}_{3}=20\right)\end{array}$ & $\begin{array}{c}\text { CN 1 } \\
\left(\mathrm{n}_{1}=98\right)\end{array}$ & $\begin{array}{c}\text { CN 2 } \\
\left(\mathrm{n}_{2}=16\right)\end{array}$ & $\begin{array}{c}\text { CN 3 } \\
\left(\mathrm{n}_{3}=11\right)\end{array}$ \\
\hline A disciplina a que se respeita o manual & 3,7 & 0,0 & 0,0 & 15,3 & 6,3 & 0,0 \\
\hline Outra disciplina & 0,0 & 0,0 & 0,0 & 8,2 & 0,0 & 0,0 \\
\hline Duas ou mais disciplinas & 0,0 & 0,0 & 0,0 & 0,0 & 0,0 & 0,0 \\
\hline $\begin{array}{l}\text { A disciplina a que respeita e outra(s) } \\
\text { disciplina(s) }\end{array}$ & 96,3 & 100,0 & 100,0 & 76,5 & 93,7 & 100,0 \\
\hline
\end{tabular}

A Tabela 9 apresenta o resultado da análise da aceitação, ou não, de diversidade de respostas às questões incluídas nos manuais escolares de Ciências analisados. Constata-se que, nos manuais CFQ 1, CFQ 2 e CN 1, a maior parte das questões assume a existência de uma única resposta. As questões incluídas nos restantes três manuais aceitam, explícita ou implicitamente, uma diversidade de respostas.

Tabela 9 - Aceitação de diversidade de respostas às questões incluídas nos manuais escolares (\%)

\begin{tabular}{|l|l|l|l|l|l|l|l|}
\hline \multicolumn{2}{|l|}{ Aceitação de diversidade das respostas } & $\begin{array}{l}\text { CFQ 1 } \\
\left(n_{1}=27\right)\end{array}$ & $\begin{array}{l}\text { CFQ 2 } \\
\left(n_{2}=3\right)\end{array}$ & $\begin{array}{l}\text { CFQ 3 } \\
\left(n_{3}=20\right)\end{array}$ & $\begin{array}{l}\text { CN 1 } \\
\left(n_{1}=98\right)\end{array}$ & $\begin{array}{l}\text { CN 2 } \\
\left(n_{2}=16\right)\end{array}$ & $\begin{array}{l}\text { CN 3 } \\
\left(n_{3}=11\right)\end{array}$ \\
\hline \multirow{2}{*}{$\begin{array}{l}\text { Assume a existência de uma } \\
\text { única resposta }\end{array}$} & Explicitamente & 55,6 & 33,4 & 45,0 & 87,8 & 31,3 & 0,0 \\
\cline { 2 - 9 } & Implicitamente & 0,0 & 33,3 & 0,0 & 3,1 & 6,3 & 0,0 \\
\hline $\begin{array}{l}\text { Aceita a diversidade de } \\
\text { respostas }\end{array}$ & Explicitamente & 37,0 & 0,0 & 45,0 & 6,0 & 18,7 & 100,0 \\
\cline { 2 - 9 } & Implicitamente & 7,4 & 33,3 & 10,0 & 3,1 & 43,7 & 0,0 \\
\hline $\begin{array}{l}\text { Aceita a possibilidade de não } \\
\text { haver resposta }\end{array}$ & Explicitamente & 0,0 & 0,0 & 0,0 & 0,0 & 0,0 & 0,0 \\
\cline { 2 - 9 } & Implicitamente & 0,0 & 0,0 & 0,0 & 0,0 & 0,0 & 0,0 \\
\hline Não há condições para afirmar & 0,0 & 0,0 & 0,0 & 0,0 & 0,0 & 0,0 \\
\hline
\end{tabular}

\section{Considerações finais}

A aplicação a manuais de diferentes disciplinas e a diferentes manuais da mesma disciplina evidenciou diferenças, quer entre as disciplinas quer dentro 
de cada disciplina. Isto significa que a grelha parece ser válida para o objetivo para que foi construída. Por limitações de espaço não nos foi possível apresentar evidências de como a grelha foi aplicada. Em outros trabalhos, quando nos encontrávamos ainda em fase de desenvolvimento parcial da grelha, apresentamos já alguns exemplos de como isso foi feito para algumas das dimensões consideradas, o que pode ajudar o leitor interessado a perceber melhor o seu funcionamento.

No entanto, há categorias que, embora fazendo sentido teoricamente ou na base do conhecimento que temos dos manuais escolares, não foram úteis nesta análise. Pensamos que seria apropriado continuar a validação desta grelha aplicando-a a outras unidades, de natureza diferente, a fim de testar melhor a utilidade e a adequação das categorias propostas. Além disso, cremos que será interessante aplicar esta grelha a manuais escolares de outros níveis de ensino, a fim de avaliar a necessidade, ou não, de alteração da mesma para que se adéque a esses novos níveis de ensino.

Acreditamos que, eventualmente com algumas alterações, esta grelha pode ser útil para analisar o questionamento, designadamente do professor, em sala de aula ou apresentado por outros materiais, mais ou menos convencionais. Além disso, e pensando em termos mais didáticos, a grelha pode ser usada na formação inicial e contínua de professores, como instrumento de trabalho em contextos de análise e reflexão do questionamento, seja apresentado em materiais didácticos utilizados pelos professores, seja para provocar a reflexão sobre as suas próprias concepções e práticas.

\section{REFERÊNCIAS}

ALLEN, D.; TANNER, K. Approaches to cell biology teaching: questions about questions. Cell Biology Education, USA, v. 1, p. 63-67, 2002.

CHIAPPETTA, E.; FILLMAN, D. Analysis of Five High School Biology Textbooks Used in the United States for Inclusion of the Nature of Science. International Journal of Science Education, Houston (USA), v. 29, n. 15, p. 1847-1868, 2007.

CHIN, C.; CHIA, L. Problem-Based Learning: Using Students' Questions to Drive Knowledge Construction. Studies in Science Education, Nova York, v. 44, n. 1, p. 1-39, 2004.

CORREIA, M. Resolução de problemas em Física antes e após a reforma curricular. Dissertação (Mestrado em Física) - Escola de Ciências, Universidade do Minho, Braga, 1996. 
COSTA, J. et al. An analysis of question asking on scientific texts explaining natural phenomena. Journal of Research in Science Teaching, v. 37, n. 6, p. 602-614, 2000.

DAHLGREN, M.; ÖBERG, G. Questioning to learn and learning to question: Structure and function of problem-based learning scenarios in environmental science education. Higher Education, Dordrecht (Netherlands), v. 41, p. 263-282, 2001.

DEB. Currículo Nacional do Ensino Básico. Lisboa: Ministério da Educação, 2001. Disponível em: $<$ http://www.dgidc.min-edu.pt/ensinobasico/index.php?s=directorio\&pid=2>. Acesso em: 15/11/2011.

DOURADO, L.; LEITE, L. Questionamento em manuais escolares de Ciências: que contributos para a Aprendizagem Baseada na Resolução de Problemas da "sustentabilidade na Terra"? In: CONGRESSO DE ENSINANTES DE CIÊNCIA DE GALIZA, 22. 2010. Anais... Náron: Asociación de Ensinantes de Ciência de Galiza, 2010. Disponível em: <http://repositorium.sdum.uminho.pt/handle/1822/11295>. Acesso em: 14/11/2011.

FERREIRA, A. Questionamento nos professores. Seu contributo para a integração curricular. Dissertação (Mestrado em Gestão Curricular) - Departamento de Didáctica e Tecnologia Educativa, Universidade de Aveiro, Aveiro, 2010.

KAHVECI, A. Quantitative Analysis of Science and Chemistry Textbooks for Indicators of Reform: A Complementary Perspective. International Journal of Science Education, Oxon (UK), v. 32, n. 11, p. 1495-1519, 2010.

LAMBROS, A. Problem-Based Learning in middle and high school classrooms. Thousand Oaks: Corwin Press. 2004.

LEITE, L.; PALMA, C. Formulação de questões, educação em ciências e aprendizagem baseada na resolução de problemas: um estudo com alunos portugueses do $8 .^{\circ}$ ano de escolaridade. In: CONGRESO INTERNACIONAL APRENDIZAJE BASADO EN PROBLEMAS (PBL-ABP). Anais... Peru: 2006. Disponível em: < http://repositorium. sdum.uminho.pt/handle/1822/5541>. Acesso em: 09/10/2011.

;AFONSO, A. Aprendizagem baseada na resolução de problemas: Características, organização e supervisão. Boletin das Ciências, Santiago de Compostela, v. 48, p. 253 260, 2001. Disponível em: <http://repositorium.sdum.uminho.pt/ handle/1822/5538>. Acesso em: 10/11/2011.

; COSTA, C.; ESTEVES, E. Os manuais escolares e a aprendizagem baseada na resolução de problemas. In: CONGRESSO DE ENSINANTES DE CIÊNCIA DE GALIZA, 21., 2008. Anais... Carballino: Asociación de Ensinantes de Ciência de Galiza, 2008. Disponível em: $<$ http://repositorium.sdum.uminho.pt/handle/1822/9863>. Acesso em 14/11/2011. 
; DOURADO, L.; MORGADO, S. Science Textbooks as Questioning and Problem-Based Teaching and Learning Promoters: Change or Continuity? In: International Study Association on Teachers and Teaching (ISATT). Proceedings of the 15th Biennial of the ISATT Back to the Future: Legacies, Continuities and Changes in Educational Policy, Practice and Research. Braga: Centro de Investigação em Educação (CIEd), 2011.

; LOUREIRO, I.; OLIVEIRA, P. Putting PBL into Practice: powers and limitations of different types of scenarios. In: NATA, R. (Ed.). Progress in Education, Nova York: Nova Science Publishers, v. 18, p. 139-157, 2010.

LOUREIRO, I. A Aprendizagem Baseada na Resolução de Problemas e a formulação de questões a partir de contextos problemáticos: um estudo com professores e alunos de Física e Química. Dissertação (Mestrado em Educação) - Instituto de Educação e Psicologia, Universidade do Minho. Braga, 2008. Disponível em: < http://repositorium. sdum.uminho.pt/handle/1822/8152>. Acesso em: 15/11/2011.

OLIVEIRA, P. A formulação de questões a partir de contextos problemáticos: um estudo com alunos dos Ensinos Básico e Secundário. Dissertação (Mestrado em Educação) Instituto de Educação e Psicologia, Universidade do Minho. Braga, 2008. Disponível em: <https://repositorium.sdum.uminho.pt/handle/1822/8168>. Acesso em: 15/11/2011.

PEDROSA DE JESUS, H.; MOREIRA, A. The role of students questions in aligning teaching, learning and assessment: a case study from undergraduate sciences. Assessment \& Evaluation in Higher Education, v. 34, n. 2, p. 193-208, 2009.

RODRIGUES, M. A sequência discursiva pergunta-resposta. In: FONSECA, J.; BARROS, C.; RODRIGUES, C. (Eds). A organização e o funcionamento dos discursos: estudos sobre o Português. Tomo II, v. 9. Porto: Porto Editora, 1998, p. 11-220.

VASCONCELOS, C.; TORRES, J.; DOURADO, L., LEITE, L. Questions in science textbooks: Do they prompt students' inquiry and problem-based learning? In: ESERA Conference Book of Abstracts. Lyon, 2011, p. 266.

WRAGG, E.; BROWN, G. Questioning in the secondary school. London: Routledge Falmer, 2001.

ZUCKER, T. et al. Preschool Teachers' Literal and Inferential Questions and Children's Responses during Whole-class Shared Reading. Early Childhood Research Quarterly, USA, v. 25, p. 65-83, 2010.

Texto recebido em 23 de novembro de 2011.

Texto aprovado em 14 de dezembro de 2011. 